\title{
Validation and Application of the Room Model of the Modelica Buildings Library
}

\author{
Thierry Stephane Nouidui, Kaustubh Phalak, Wangda Zuo, Michael Wetter \\ Simulation Research Group, Building Technology and Urban Systems Department \\ Environmental Energy Technologies Division, Lawrence Berkeley National Laboratory \\ One Cyclotron Road, 94720, Berkeley, CA \\ TSNouidui@lbl.gov
}

\begin{abstract}
The Modelica Buildings library contains a package with a model for a thermal zone that computes heat transfer through the building envelope and within a room. It considers various heat transfer phenomena of a room, including conduction, convection, shortwave and long-wave radiation. The first part of this paper describes the physical phenomena considered in the room model. The second part validates the room model by using a standard test suite provided by the American Society of Heating, Refrigerating and Air-Conditioning Engineers (ASHRAE). The third part focuses on an application where the room model is used for simulation-based controls of a window shading device to reduce building energy consumption.
\end{abstract}

Keywords: Buildings library; ANSI/ASHRAE Standard 140; Simulation-Based Controls

\section{Introduction}

To support the design and operation of low energy buildings, the Lawrence Berkeley National Laboratory (LBNL) has been developing a free and open source Modelica Buildings library for building energy and control systems [1]. Version 1.1 Build1 of the library contains about 200 component models for building energy and control systems. These component models can be used for (1) rapid prototyping of innovative building systems, (2) design of building energy systems, (3) performance analysis of existing building systems, (4) development, specification and optimization of building control sequences, and (5) model-based operation for controls, fault detection and diagnostics.

Recently, we implemented window and room models into the Buildings library to extend its capability to whole building energy simulation [2]. However, the models were not systematically validated against reference data in [2]. In [3], we presented the valida- tion of the window model which is an important part of the room model. This paper is to validate the room model and to show an application where the model is used as part of a controls framework of a window shading device of a building. After the introduction, we will briefly describe the physics and implementation of the room model. Then we will validate the room model using a subset of ANSI/ASHRAE Standard 140 [4], which is a standard test suite for evaluating building energy simulation tools. After validating the room model, we will describe an application where the room model is part of a simulation-based controls framework used to control a window shading device of a test cell for reducing building energy consumption.

\section{Room model}

The room model of the Buildings library simulates heat transport processes within rooms and through the building envelope. This model can be used for the modeling of rooms with unlimited number of opaque and transparent surfaces or entire buildings. The room model takes into account the following physical processes:

(1) Transient or steady-state heat conduction through opaque surfaces, such as walls.

(2) Heat transfer through glazing systems including solar radiation, infrared radiation from ambient environment, heat conduction and heat convection.

(3) Convective heat transfer between the room (inside) air and room-facing surfaces using either a constant heat transfer coefficient or a temperaturedependent heat transfer coefficient.

(4) Convective heat transfer between the outside air and outside-facing surfaces using either a constant heat transfer coefficient or a variable heat transfer coefficient as a function of wind-speed, winddirection and temperature.

(5) Solar and infrared heat transfer between the room enclosing surfaces. 
(6) Temperature, pressure and species balance equations inside the room volume.

Note that the current room model assumes that the air in the room is well-mixed so that a single volume is used to represent the room air. More details of the room model are available in [2].

\section{Validation of the room model}

This section focuses on validation of the room model using different cases of ANSI/ASHRAE Standard 140 [4]. The Standard 140 is widely used in the building simulation community for testing the accuracy of building simulation models. Due to the complexity and high cost, it is difficult to precisely measure the energy performance of a building for a year. As an alternative approach, Standard 140 documents the simulated annual energy performance of a thermal zone using different building energy simulation tools. The simulation results of the tools are not the same since they use different assumptions, physical models and implementations. However, the variation of the simulation results is usually in a reasonable range. In this paper, we present validation cases of a low and high mass building using cases $600,610,620,630,600 \mathrm{FF}, 900$, and 900FF.

\section{Model configuration}

For the validation, the following model configurations have been used:

- Room-side convective heat transfer coefficients are a function of the difference between air and surface temperature.

- Outside convective heat transfer coefficients are a function of the difference between air and surface temperature, and a function of wind speed.

- The long-wave radiative heat transfer has not been linearized.

- The medium model Buildings.Media.GasesConstantDensity.SimpleAir has been used.

For more details, all cases are available in the Buildings library version 1.2

\subsection{Case 600: Low mass building without shad- ing (South facing windows)}

Case 600 is a low mass rectangular zone $(6 \mathrm{~m} \times 8 \mathrm{~m} \times$ $2.7 \mathrm{~m})$ without interior partition and with two windows $(3 \mathrm{~m} \times 2 \mathrm{~m}$ each) on the south wall (Figure 1$)$. Construction material properties and other details are provided in [4]. For the validation, we simulated the zone for a year with weather data provided in [4].

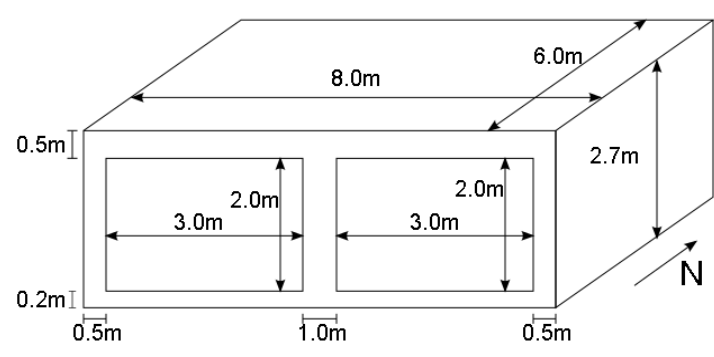

Figure 1 Case 600: Low mass rectangular zone

Figure 2 compares the annual heating and cooling loads calculated by the room model of the Buildings library with results of other energy simulation tools provided in [4]. The results of the room model, labeled as Buildings Lib., are comparable with other energy simulation tools. The heating $(5.44 \mathrm{MWh})$ and cooling $(6.97 \mathrm{MWh})$ loads are within the range specified in [4] .

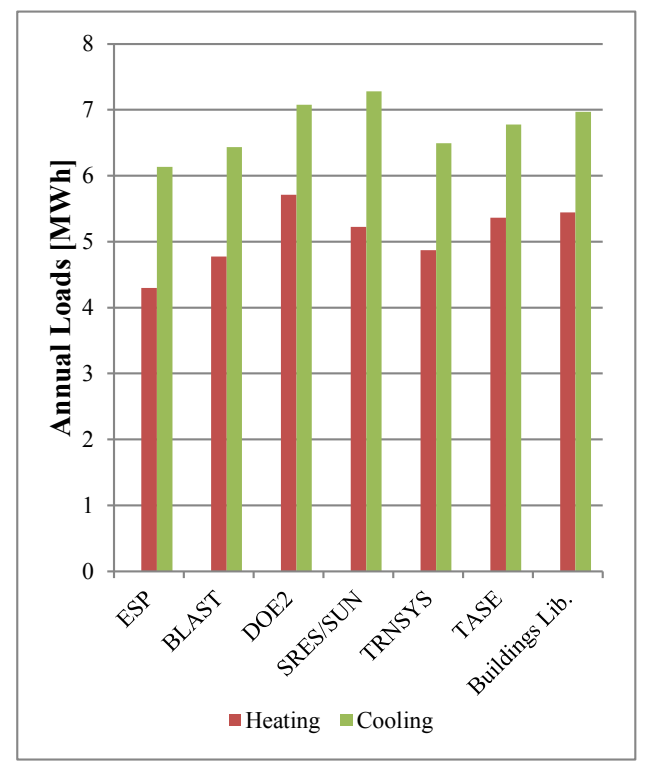

Figure 2 Case 600: Comparison of annual heating and cooling loads

We also compared the predicted peak heating load (Table 1) and peak cooling load (Table 2) and their time of occurrence. Again, the results of the Buildings library are in close agreement with simulation results of other tools. The difference observed in date of peak cooling load can be caused by different modeling assumptions in the simulation tools. The peak heating $(4.23 \mathrm{~kW})$ and cooling $(6.82 \mathrm{~kW})$ loads predicted by the Buildings library are within the minimum and maximum range specified in [4]. 
Table 1 Case 600: Annual hourly integrated peak heating loads

\begin{tabular}{|l|c|c|c|}
\hline Code Name & $k W$ & Date & Hour \\
\hline ESP & 3.437 & 4-Jan & 5 \\
\hline BLAST & 3.940 & 4-Jan & 5 \\
\hline DOE2 & 4.045 & 4-Jan & 5 \\
\hline SRES/SUN & 4.258 & 4-Jan & 2 \\
\hline TRNSYS & 3.931 & 4-Jan & 6 \\
\hline TASE & 4.354 & 4-Jan & 2 \\
\hline Buildings Lib. & 4.229 & 4-Jan & 5 \\
\hline
\end{tabular}

Table 2 Case 600: Annual hourly integrated peak cooling loads

\begin{tabular}{|c|c|c|c|}
\hline Code Name & $k W$ & Date & Hour \\
\hline ESP & 6.194 & 17-Oct & 13 \\
\hline BLAST & 5.965 & 16-Oct & 14 \\
\hline DOE2 & 6.656 & 16-Oct & 13 \\
\hline SRES/SUN & 6.827 & 16-Oct & 14 \\
\hline TRNSYS & 6.486 & 16-Oct & 14 \\
\hline TASE & 6.812 & 17-Oct & 14 \\
\hline Buildings Lib. & 6.821 & 17-Oct & 13 \\
\hline
\end{tabular}

Figure 3 shows hourly load profiles on the day of peak heating load $\left(\operatorname{Jan} 4^{\text {th }}\right)$. In the load profiles, heating and cooling loads are represented with positive and negative values respectively. The Buildings library predicted that there was cooling load from about 11 a.m. to 5 p.m. and heating load for the rest of the day. This profile is similar to the profiles predicted by other simulation tools.

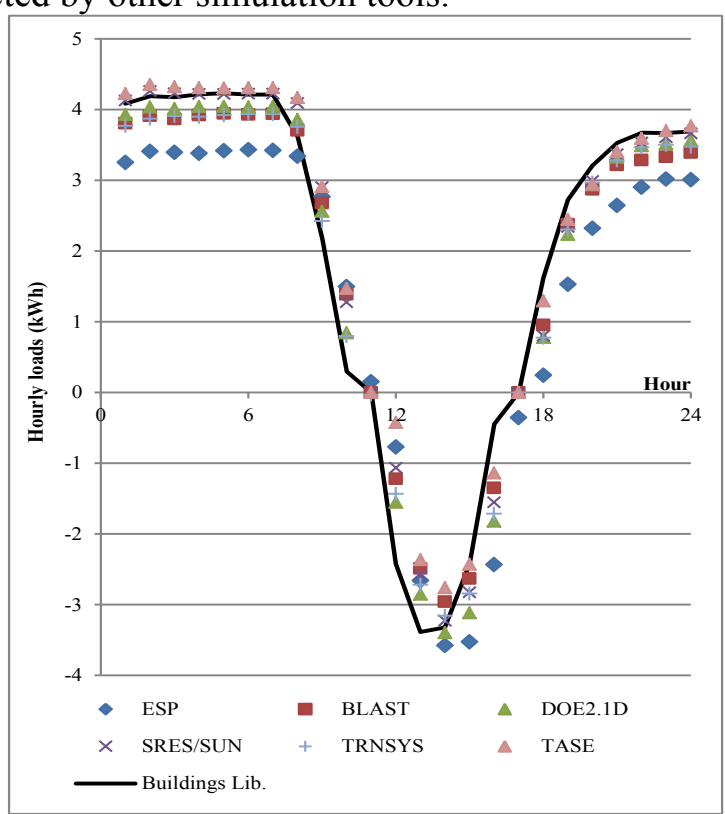

Figure 3 Case 600: Comparison of hourly heating and cooling load profiles for Jan $4^{\text {th }}$

\subsection{Case 610: Low mass building with shading (overhang)}

The case 610 is an extension of Case 600 in which a horizontal overhang is added to provide shading for the south facing windows. The overhang is $1 \mathrm{~m}$ deep, located at $0.5 \mathrm{~m}$ above the windows and extends from east to west facing walls as shown in Figure 4. This case tests the ability of a simulation tool to treat shading of a south exposed window.

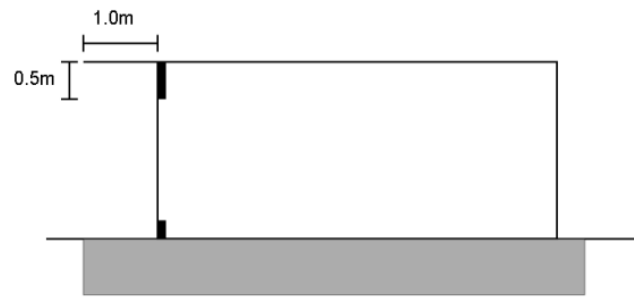

Figure 4 Case 610: Low mass building with overhang on south facing windows

Figure 5 compares the annual heating and cooling loads calculated by the Buildings Library with other simulation tools. The heating (5.47 MWh) and cooling $(5.39 \mathrm{MWh})$ loads predicted by the Buildings library are within minimum and maximum range specified in [4]. As expected, adding shading device reduced the total cooling load. Compared to Case 600 , the reduction in cooling load varied from $19 \%$ to $36 \%$ for different energy simulation tools. The Buildings library predicted a reduction of $23 \%$. With less solar gain, all the programs also predicted increased $(0.5 \%$ to $2 \%)$ heating load. The Buildings library predicted a minor increase of $0.6 \%$.

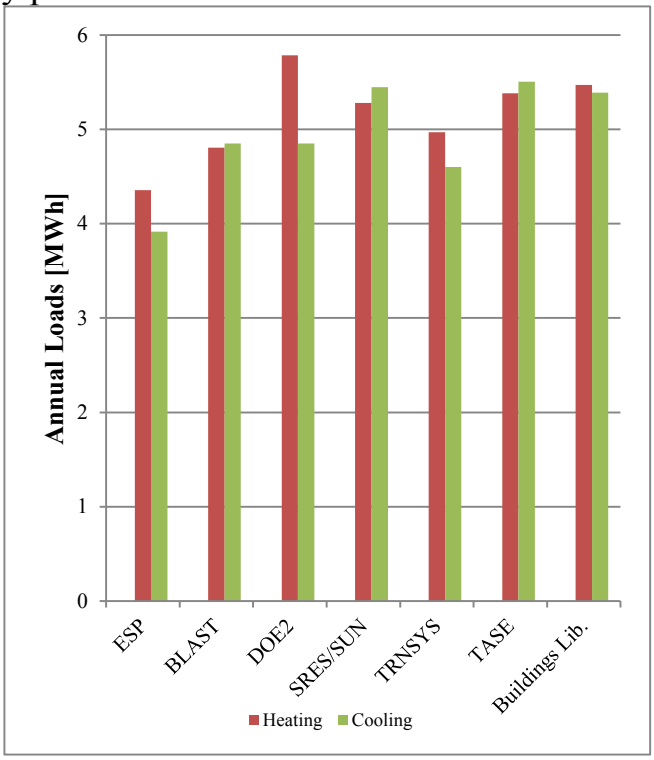

Figure 5 Case 610: Comparison of annual heating and cooling loads

Table 3 and Table 4 compare the predicted peak heating and cooling load and time of occurrence during the year. All simulation tools predicted almost similar time for the occurrence of the peak heating load. For peak cooling loads, two simulation tools predicted significantly different dates than the rest of the simulation tools. The room model predicted the same date as the majority of the tools. The Buildings 
library calculated a peak heating load of $4.23 \mathrm{~kW}$ which is within the range of reference data. However, it slightly over-predicted the peak cooling load (6.38 $\mathrm{kW}$ ) which is about $0.15 \%$ higher than the maximum value $(6.37 \mathrm{~kW})$ of the reference data.

Table 3 Case 610: Annual hourly integrated peak heating loads

\begin{tabular}{|l|c|c|c|}
\hline Code Name & $\mathrm{kW}$ & Date & Hour \\
\hline ESP & 3.437 & 4-Jan & 5 \\
\hline BLAST & 3.941 & 4-Jan & 5 \\
\hline DOE2 & 4.034 & 4-Jan & 5 \\
\hline SRES/SUN & 4.258 & 4-Jan & 2 \\
\hline TRNSYS & 3.922 & 4-Jan & 6 \\
\hline TASE & 4.354 & 4-Jan & 2 \\
\hline Buildings Lib. & 4.228 & 4-Jan & 5 \\
\hline
\end{tabular}

Table 4 Case 610: Annual hourly integrated peak cooling loads

\begin{tabular}{|l|c|c|c|}
\hline Code Name & $k W$ & Date & Hour \\
\hline ESP & 5.669 & 25-Nov & 13 \\
\hline BLAST & 5.824 & 25-Nov & 14 \\
\hline DOE2 & 6.064 & 13-Jan & 14 \\
\hline SRES/SUN & 6.371 & 25-Nov & 14 \\
\hline TRNSYS & 5.675 & 25-Nov & 14 \\
\hline TASE & 6.146 & 17-Oct & 14 \\
\hline Buildings Lib. & 6.380 & 25-Nov & 13 \\
\hline
\end{tabular}

\subsection{Case 620: Low mass building without shad-} ing (East-West facing windows)

The case 620 is same as Case 600 except that windows are oriented towards east and west as shown in Figure 6.
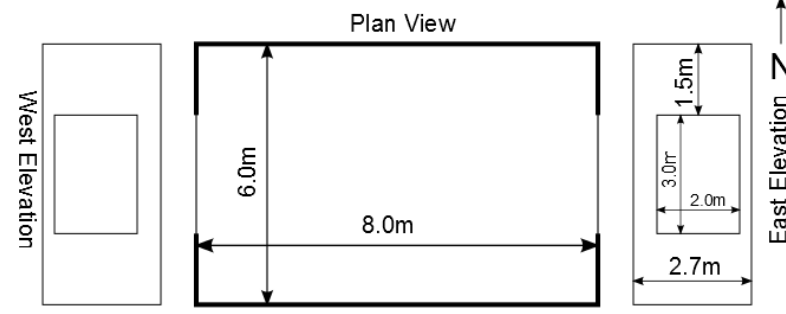

Figure 6 Case 620: East and West facing windows

Figure 7 compares annual heating and cooling loads computed by Buildings Library with other simulation tools. The results of room model (heating load: 5.61 MWh and cooling load: 4.31 MWh) are comparable with other simulation tools and are within the range specified in [4]. In contrast to Case 600 here heating load is higher than cooling as the room receives solar radiation during morning and evening when intensity of solar irradiation on the window surface is low, and during midday when the azimuth angle with respect to the window surface is high and the normal component of irradiation is low. Also both windows are never simultaneously exposed to the sun.

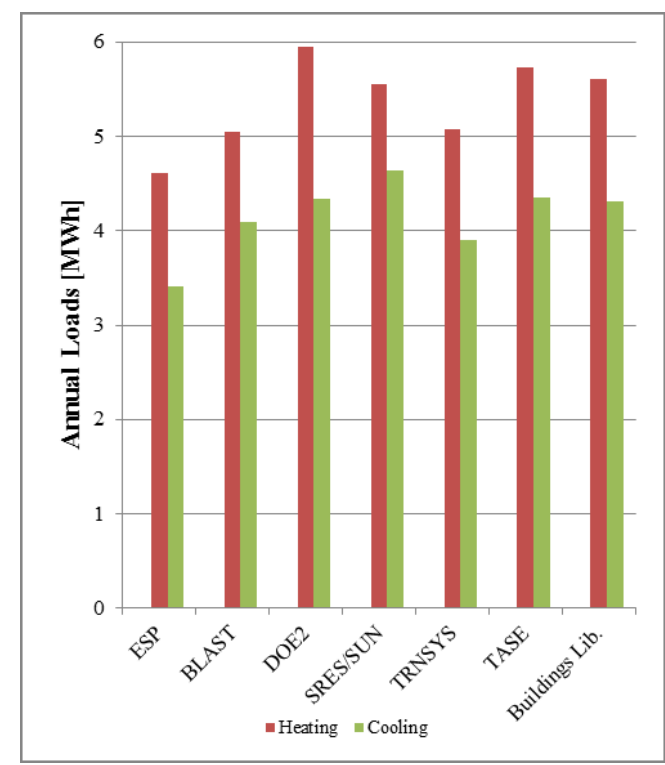

Figure 7 Case 620: Comparison of annual heating and cooling loads

Peak heating and cooling load with their time of occurrence is compared in Table 5 and Table 6. The results are comparable and are within range specified in [4]. Compared to Case 600 and Case 610 there is no significant change in peak heating load but peak cooling has reduced. This reduction is due to low solar heat gain as discussed earlier.

Table 5 Case 620: Annual hourly integrated peak heating loads

\begin{tabular}{|l|c|c|c|}
\hline Code Name & $k W$ & Date & Hour \\
\hline ESP & 3.591 & 4-Jan & 6 \\
\hline BLAST & 3.941 & 4-Jan & 5 \\
\hline DOE2 & 4.046 & 4-Jan & 5 \\
\hline SRES/SUN & 4.277 & 4-Jan & 2 \\
\hline TRNSYS & 3.922 & 4-Jan & 6 \\
\hline TASE & 4.379 & 4-Jan & 2 \\
\hline Buildings Lib. & 4.230 & 4-Jan & 5 \\
\hline
\end{tabular}

Table 6 Case 620: Annual hourly integrated peak cooling loads

\begin{tabular}{|l|c|c|c|}
\hline Code Name & $k W$ & Date & Hour \\
\hline ESP & 3.634 & 26-Jul & 16 \\
\hline BLAST & 4.075 & 26-Jul & 17 \\
\hline DOE2 & 4.430 & 26-Jul & 17 \\
\hline SRES/SUN & 4.593 & 26-Jul & 17 \\
\hline TRNSYS & 4.275 & 26-Jul & 17 \\
\hline TASE & 5.096 & 26-Jul & 16 \\
\hline Buildings Lib. & 4.295 & 26-Jul & 16 \\
\hline
\end{tabular}

\subsection{Case 630: Low mass building with shading (overhang and window side fins)}

Case 630 is an extension of case 620 in which an overhang and side fins are added on both east and west facing windows. The overhang is $1 \mathrm{~m}$ deep, $3 \mathrm{~m}$ wide and located $0.5 \mathrm{~m}$ above the windows. The side 
fins are $1 \mathrm{~m}$ deep, along the vertical edges of the windows and extend from roof to ground level. This case tests the ability of the simulation tool to treat shading of east and west exposed windows with side fins and overhang combined.

As the east and west side windows are covered with overhang and side fins, the room receives little direct solar heat gain. This results in higher heating loads and lower cooling load. Results obtained from the Buildings library (heating load: 5.88 MWh, cooling load: $3.35 \mathrm{MWh}$ ) are comparable and within range of results from other simulation tools (Figure 8).

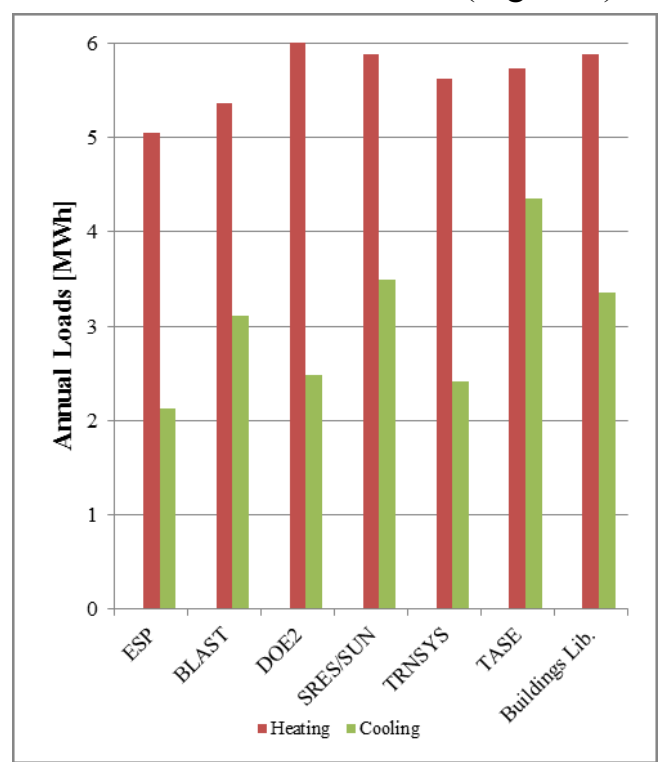

Figure 8 Case 630: Comparison of annual heating and cooling loads

Even though there is not much change in peak heating load compared to earlier cases, the peak cooling load has dropped significantly. In this case, both peak heating-cooling load and time of occurrence calculated by the Buildings library are within range and comparable with results from other tools as shown in Table 7 and Table 8.

Table 7 Case 630: Annual hourly integrated peak heating loads

\begin{tabular}{|l|c|c|c|}
\hline Code Name & $k W$ & Date & Hour \\
\hline ESP & 3.592 & 4-Jan & 7 \\
\hline BLAST & 3.941 & 4-Jan & 5 \\
\hline DOE2 & 4.025 & 4-Jan & 5 \\
\hline SRES/SUN & 4.280 & 4-Jan & 2 \\
\hline TRNSYS & 3.922 & 4-Jan & 6 \\
\hline TASE & N.A. & N.A. & N.A. \\
\hline Buildings Lib. & 4.230 & 4-Jan & 5 \\
\hline
\end{tabular}

Table 8 Case 630: Annual hourly integrated peak cooling loads

\begin{tabular}{|l|c|c|c|}
\hline Code Name & $k W$ & Date & Hour \\
\hline ESP & 3.072 & 26-Jul & 16 \\
\hline BLAST & 3.704 & 26-Jul & 17 \\
\hline DOE2 & 3.588 & 26-Jul & 17 \\
\hline SRES/SUN & 4.116 & 26-Jul & 17 \\
\hline TRNSYS & 3.608 & 26-Jul & 17 \\
\hline TASE & N.A. & N.A. & N.A. \\
\hline Buildings Lib. & 3.866 & 26-Jul & 17 \\
\hline
\end{tabular}

\section{Low mass basic sensitivity tests}

Sensitivity of each program for addition of overhang, side fins and change in window orientation is tested in [4] using differences in the results. The variation in annual and peak heating-cooling loads can be observed in Table 9 and Table 10 for Case 600 and Case 610. Results for Buildings library are within the range specified in [4].

Table 9 Difference in Case 600 and 610 results: Annual loads

\begin{tabular}{|l|c|c|}
\hline \multicolumn{1}{|c|}{ Code Name } & Heating [MWh] & Cooling $[\mathrm{MWh}]$ \\
\hline ESP & 0.059 & -2.222 \\
\hline BLAST & 0.033 & -1.582 \\
\hline DOE2 & 0.077 & -2.227 \\
\hline SRES/SUN & 0.054 & -1.830 \\
\hline TRNSYS & 0.098 & -1.891 \\
\hline TASE & 0.021 & -1.272 \\
\hline Buildings Lib. & 0.029 & -1.581 \\
\hline
\end{tabular}

Table 10 Difference in Case 600 and 610 results: Peak loads

\begin{tabular}{|l|c|c|}
\hline \multicolumn{1}{|c|}{ Code Name } & Heating $[\mathrm{kW}]$ & Cooling $[\mathrm{kW}]$ \\
\hline ESP & 0.000 & -0.525 \\
\hline BLAST & 0.001 & -0.141 \\
\hline DOE2 & -0.011 & -0.592 \\
\hline SRES/SUN & 0.000 & -0.456 \\
\hline TRNSYS & -0.008 & -0.811 \\
\hline TASE & 0.000 & -0.666 \\
\hline Buildings Lib. & -0.001 & -0.441 \\
\hline
\end{tabular}

Differences in results of case 620 and 600 represent effect of change in window orientation. The differences in results of the Buildings library (Table 11 and Table 12) for these cases are within the range specified in [4]. This indicates that the room model correctly models modification in window orientation.

Table 11 Difference in Case 600 and 620: Annual loads

\begin{tabular}{|l|c|c|}
\hline \multicolumn{1}{|c|}{ Code Name } & Heating [MWh] & Cooling [MWh] \\
\hline ESP & 0.317 & -2.72 \\
\hline BLAST & 0.276 & -2.341 \\
\hline DOE2 & 0.235 & -2.745 \\
\hline SRES/SUN & 0.328 & -2.645 \\
\hline TRNSYS & 0.201 & -2.591 \\
\hline TASE & 0.366 & -2.427 \\
\hline Buildings Lib. & 0.169 & -2.661 \\
\hline
\end{tabular}


Table 12 Difference in Case 600 and 620 results: Peak loads

\begin{tabular}{|l|c|c|}
\hline \multicolumn{1}{|c|}{ Code Name } & Heating $[\mathrm{kW}]$ & Cooling $[\mathrm{kW}]$ \\
\hline ESP & 0.154 & -2.560 \\
\hline BLAST & 0.001 & -1.890 \\
\hline DOE2 & 0.001 & -2.226 \\
\hline SRES/SUN & 0.019 & -2.234 \\
\hline TRNSYS & -0.008 & -2.211 \\
\hline TASE & 0.025 & -1.716 \\
\hline Buildings Lib. & 0.001 & -2.526 \\
\hline
\end{tabular}

As described earlier, in Case 630 overhang and side fins are added to the east and west facing windows of Case 620. The differences in results of these cases verify the effect of these shading devices. Table 13 and Table 14 compare the results of the Buildings library with other simulation tools.

Table 13 Difference in Case 620 and 630: Annual loads

\begin{tabular}{|l|c|c|}
\hline \multicolumn{1}{|c|}{ Code Name } & Heating [MWh] & Cooling [MWh] \\
\hline ESP & 0.437 & -1.288 \\
\hline BLAST & 0.310 & -0.984 \\
\hline DOE2 & 0.525 & -1.845 \\
\hline SRES/SUN & 0.329 & -1.140 \\
\hline TRNSYS & 0.551 & -1.485 \\
\hline TASE & N.A & N.A \\
\hline Buildings Lib. & 0.266 & -0.956 \\
\hline
\end{tabular}

Table 14 Difference in Case 620 and 630 results: Peak loads

\begin{tabular}{|l|c|c|}
\hline \multicolumn{1}{|c|}{ Code Name } & Heating $[\mathrm{kW}]$ & Cooling $[\mathrm{kW}]$ \\
\hline ESP & 0.001 & -0.562 \\
\hline BLAST & 0.000 & -0.371 \\
\hline DOE2 & -0.021 & -0.842 \\
\hline SRES/SUN & 0.003 & -0.477 \\
\hline TRNSYS & 0.000 & -0.667 \\
\hline TASE & N.A. & N.A. \\
\hline Buildings Lib. & 0.000 & -0.429 \\
\hline
\end{tabular}

\subsection{Case 600FF: Low mass building without temperature control}

Case $600 \mathrm{FF}$ is based on case 600 except that there is no mechanical heating or cooling system. The room temperature is floating with the weather conditions. The Buildings library computed the highest room temperature $\left(65.9^{\circ} \mathrm{C}\right)$ at 3 p.m. on October 17 and the lowest room temperature $\left(-19.8^{\circ} \mathrm{C}\right)$ at 8 a.m. on January 4 . These results are consistent with the ones computed by other simulation tools in Standard 140.

\subsection{Case 900: High mass building with temper- ature control}

Case 900 is a high mass building which uses the same building model as was used for Case 600 except that the wall and floor construction were changed to use heavier materials. This case is used to test the ability of a simulation tool to treat thermal mass. As shown in Figure 9, the Buildings library predicted annual cooling and heating loads are in the range of Standard 140. The Buildings library also predicted the occurring hour for peak heating load (3.267 KW) at 7 a.m. on January 4 and peak cooling load $(3.369 \mathrm{KW})$ at 2 a.m. on October 17. These values are also in the range of Standard 140.

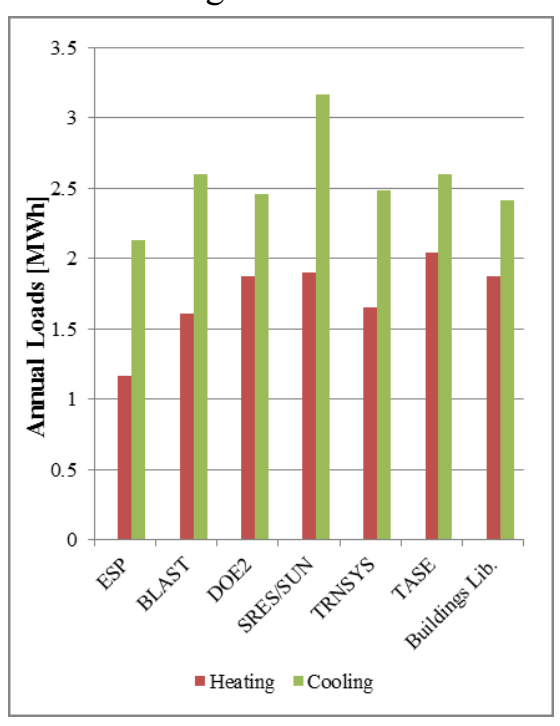

Figure 9 Case 900: Comparison of annual heating and cooling loads

\subsection{Case 900FF: High mass building without temperature control}

Case $900 \mathrm{FF}$ is the same as case 900 with the only difference that there is no mechanical heating or cooling system. The room temperature is floating. The Buildings library computed the highest room temperature $\left(42.6^{\circ} \mathrm{C}\right)$ at 3 p.m. on September 2 and the lowest room temperature $\left(-5.7^{\circ} \mathrm{C}\right)$ at 8 a.m. on January 4 . These results are consistent with the ones predicted by other simulation tools in Standard 140.

\section{Application}

This section describes an application where the validated room model of the Buildings library was used in a simulation-based controls framework to control a window shading device of one test cell of the Advanced Windows Test Facility at LBNL (Figure 10). The windows facility is a test facility with three identical test cells which serve for testing and evaluation of controls strategies and façade systems. The dry bulb temperature in the corridor of the facility (Figure 11) is controlled to a constant value and the walls of the test cells are well insulated. This is to insure that all test cells experience the same load profiles. Each of the test cells has a floor area of about $14 \mathrm{~m}^{2}$, a room volume of about $47 \mathrm{~m}^{3}$ and a south facing window. The ovals in Figure 10 indicate the test cells that were used in this study. The win- 
dow shading device of the left test cell is controlled with the controls framework. The right test cell has a static interior blind and is used as our reference cell.

The room air temperature of the test cells is controlled to a fixed temperature. There are several sensors in the test cells which measure room air temperatures, exterior glass surface temperatures at the upper and lower window surfaces, plug loads, lighting loads, fan loads as well as transmitted solar irradiation at the upper and lower window surface. There are also several sensors located outdoors to measure external environmental conditions, such as solar irradiances, outdoor temperature, and wind speed (see Figure 12).

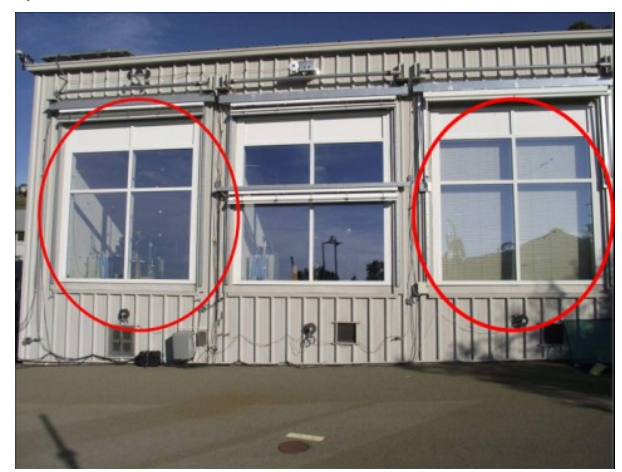

Figure 10 The Advanced Windows Test Facility at the Lawrence Berkeley National Laboratory

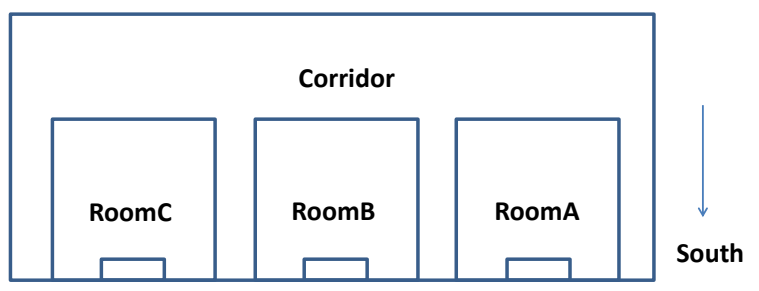

Figure 11 Schematic view of the Advanced Windows Test Facility at the Lawrence Berkeley National Laboratory

In this application, the room model of the Buildings library is used to model the test cell with the window and an exterior venetian blind. The window system installed in the test cell is a double pane window. The exterior venetian blind can be remotely controlled to be fully retracted or fully closed. It is also possible to control the slat angle positions of the blind.

In the following sections, we will describe the controls framework applied to control the blind of the window system. The objective of the framework is to control the blind to reduce heating and cooling loads of the test cell. The indoor dry-bulb temperature was controlled to a constant value of $24^{\circ} \mathrm{C}$. To reduce the heating and cooling loads, an optimal blind position is calculated at discrete time steps using Modelica models of the Buildings library and a control algorithm. This position is then converted into a control signal which is sent to real hardware to move the blind in the desired position.

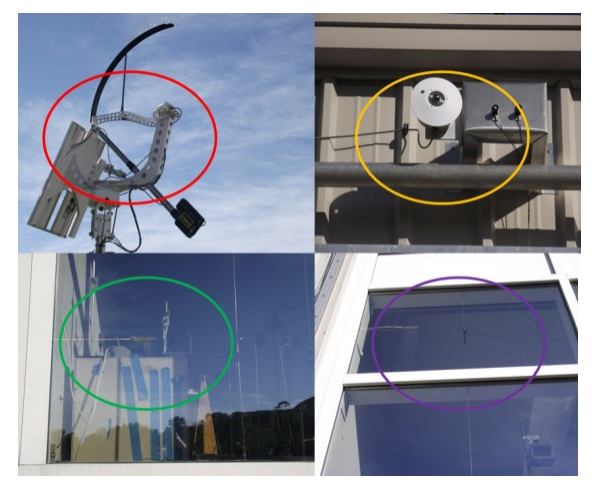

Figure 12 Instrumentation used at the test facility (Pyranometer (top left), pyrgeometer (top right), temperature sensors (bottom left), pyranometer (bottom right))

\subsection{Overview of the Controls Framework}

Figure 13 shows the schematic of the framework for one simulation time step. It involves the cosimulation between different simulation tools and the communication between hardware and software. The entire process is controlled by the Building Controls Virtual Test Bed (BCVTB) [5]. The BCVTB is an open source software environment developed by LBNL and based on the Ptolemy II software from UC Berkeley [6]. It allows expert users to couple different simulation programs for co-simulation, and to couple simulation programs with actual hardware [7].

In the controls framework, the BCVTB is the master that orchestrates the simulations and data exchange among simulators and hardware. It sets the start time, the stop time as well as the sampling time when blind position should be updated. It uses the System Command actor [5] to call scripts which start different simulation programs. In our implementation, the simulation runs in real-time with a time step size of 5 minutes.

The simulation workflow can be divided into 8 steps. At the beginning of the simulation, the BCVTB gets the start and end time of the simulation, the test cell number, and the time step that are predefined by the users.

In step (1) of every time step, it uses a Python [8] script to send requests through the internet to get the current clock-time, weather data, as well as plug, fan and lighting loads which are measured in the test cell.

In step (2), it writes a weather file and a load file. The weather file contains measured weather data including diffuse solar irradiation on the horizontal surface, direct solar irradiation, the atmospheric infrared solar irradiation, outdoor dry-bulb tempera- 
ture, and wind speed. The load file contains the sum of plug, fan and lighting loads.

In step (3), the BCVTB starts a Perl [9] script which invokes Radiance [10] to calculate the incoming solar irradiations and the solar radiation absorbed by different room surfaces for multiple blind positions. Radiance is a ray-tracing based daylighting simulation program. It is selected because it can compute light transmittance of complex fenestration systems with light-redirecting shades. Since the Buildings library does not support the modeling of venetian blinds, we use the capability of Radiance to compute the light redirection of the blinds, and to compute the solar irradiation distribution in the room. This was achieved by calculating incident and absorbed solar irradiation in Radiance for distinct blind positions and overwriting the solar irradiation distribution calculations done in the room model. In our configuration, we considered 11 positions. Because the simulations were fast compared to the sampling time, and only 11 control options need to be considered, we did an exhaustive search to determine the optimal control signal. The first position is with the blind fully retracted. The second to the $11^{\text {th }}$ position are with the blind set at angles with degree of 40,35 , $30,25,20,15,10,5,0$, and -5 , respectively, where the last position is with the blind fully closed. The calculated irradiation data includes incident solar radiation on interior wall surfaces of the test cell and solar irradiation absorbed in glass layers and the shading layer of the window system. At the end of the calculation, the results are written to the files which will be used for step (4).

In step (4), the BCVTB starts a script, which simulates multiple instances of the Modelica room model using Dymola [11]. Each model represents the room with the blind set to a specific position. The model is parameterized using a weather file, load file as well as incoming and absorbed solar irradiation pre-calculated by Radiance. Figure 14 shows a screenshot of the Modelica implementation of the test cell. This model consists of 7 parts: part 1 defines the heat sources which are read from the load file, part 2 is the PI controller for heating, part 3 is the PI controller for cooling, part 4 models the building envelope, part 5 represents the material properties of the building envelope, part 6 provides the weather data, and part 7 computes the infiltration in the test cell.

In step (5), the BCVTB calls a Python script to collect the Modelica simulation results for different blind positions and determines the optimal position which will lead to the least heating and cooling load. This position is then written in a file named "chosenposition.txt".

In step (6), the BCVTB calls a script which saves the state variables of the room model with the optimal blind position. These state variables will be used as initial conditions in the next time step. The capability of Modelica to easily reinitialize state variables, the transparency of making changes to models and the separation between process model, control implementation and numerical methods are important reasons why Modelica being well suited suitable for simulation-based controls operations.

In step (7), the BCVTB calls a script which reads the optimal blind position from the "chosenposition.txt" file, converts it into a controls signal, and sends it through the internet to the actuator to set the position of the blind.

Finally, in step (8), the BCVTB calls a script which requests the hardware to report the actuation position set. This is written it in a $\log$ file. The BCVTB then pauses until the next time step is reached and restarts the process.

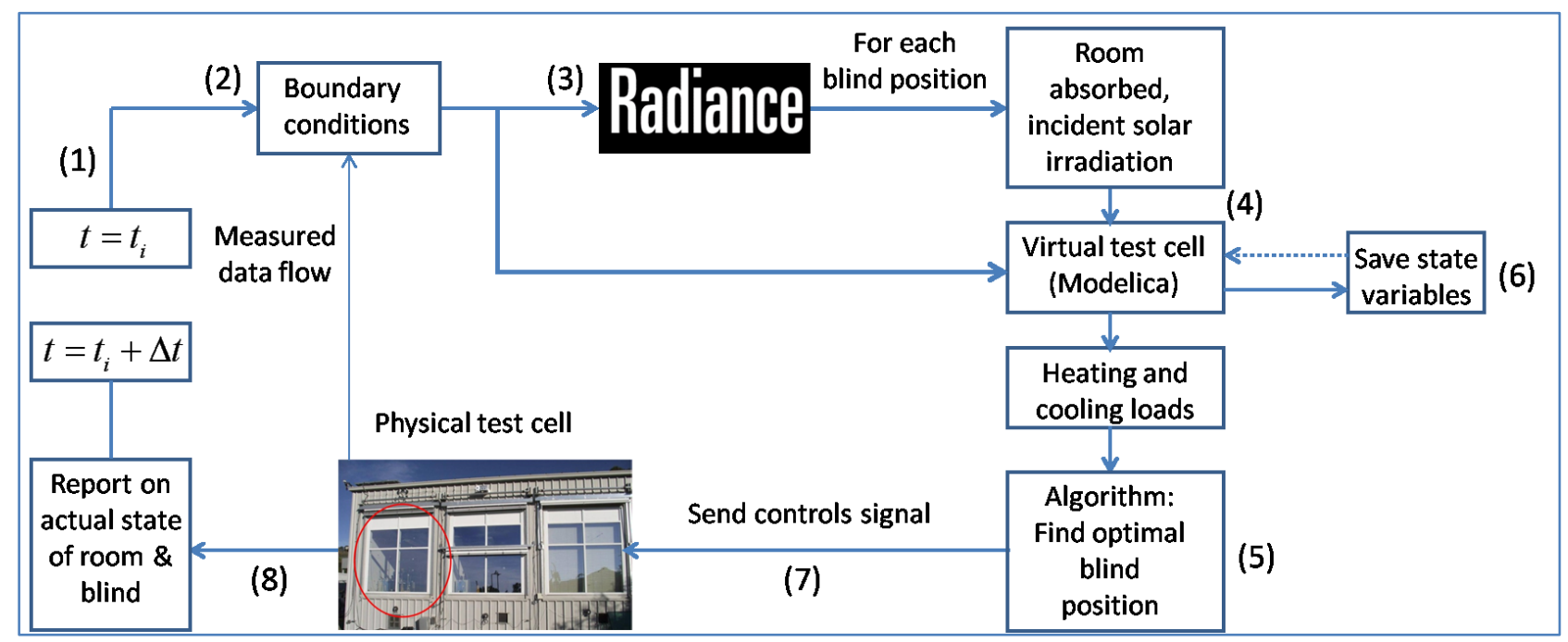

Figure 13 Simulation-based controls framework used to control one of the test cells of the test facility 


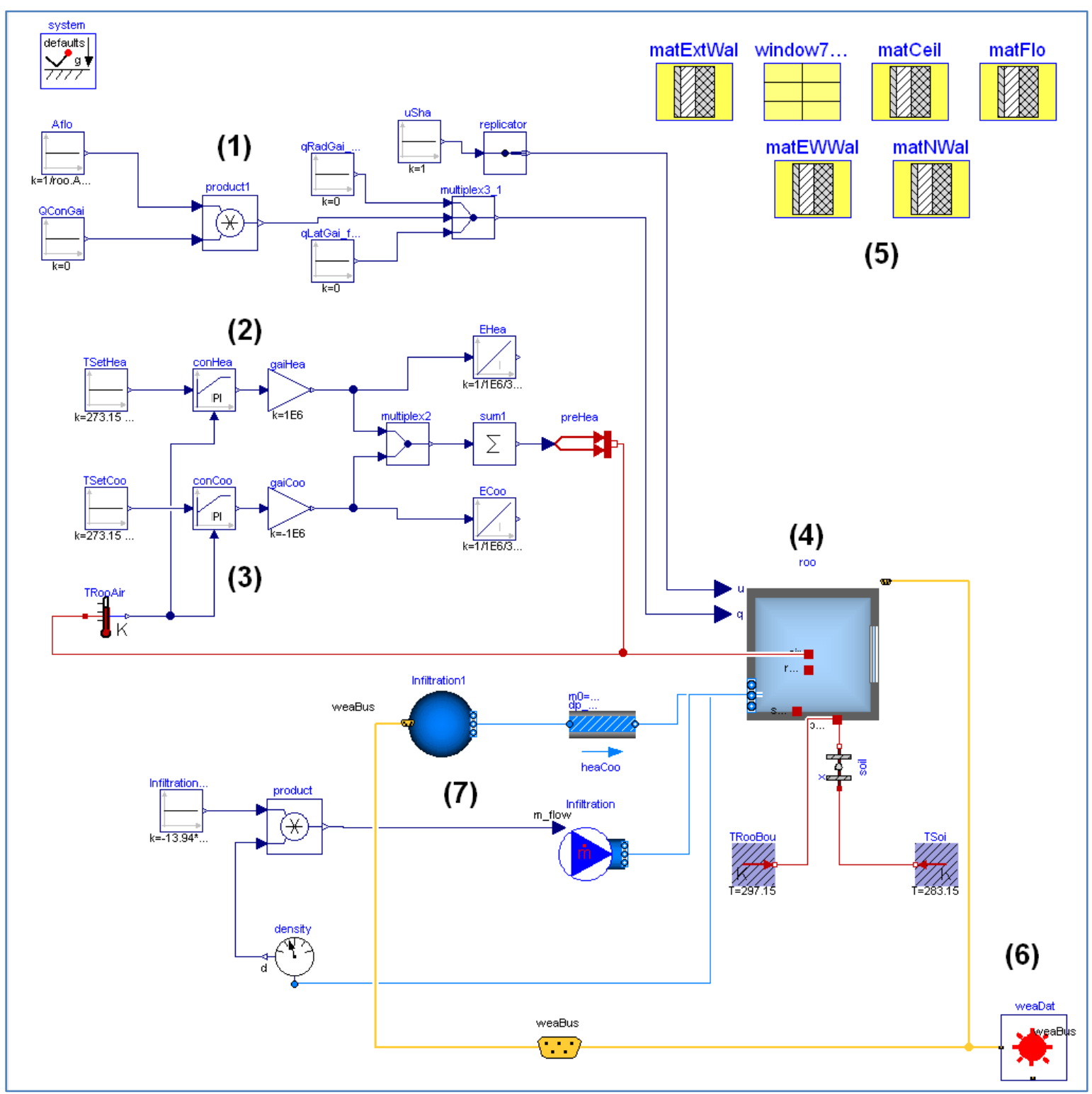

Figure 14 Modelica implementation of the test cell

\subsection{Simulation results}

In our preliminary work, we measured the heating and cooling loads of two test cells for a period of 9 days (from 04/13/2012 to 04/22/2012). One test cell used an interior static venetian blind set at 30 degree blocking angle (RoomA). This represents one common configuration for blinds which is generally set by users. The other test cell (RoomC) has an exterior blind controlled using the simulation-based controls framework.

As shown in Figure 16 the heating and cooling load of the test cell with controlled exterior venetian blind is much less than that with the interior static blind. The measurements show in the peak up to two and half times lower cooling load in the room with the controlled exterior venetian blind. Consequently, one can save cooling energy by using the controlled exterior venetian blind.

Considering the test was only about one week and there were days with missing data, further investigations are needed to evaluate the performance of the algorithm over a longer period of time. Both exterior blind and controls can contribute to the energy saving in current study. To quantify the energy saving due to the controls, we will need to use exterior venetian blinds for both test cells. Nevertheless, the preliminary results show that our controls framework is functioning and the Modelica room model can meet the requirements of the application. 


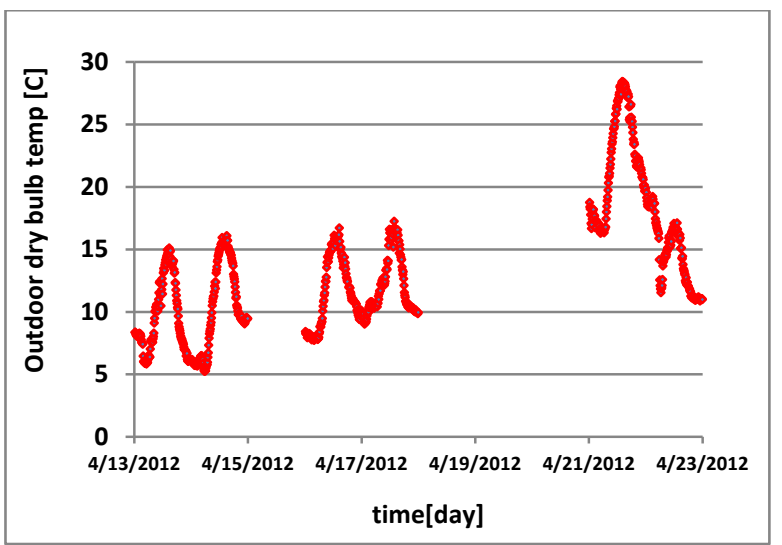

Figure 15 Measured outdoor dry bulb temperature

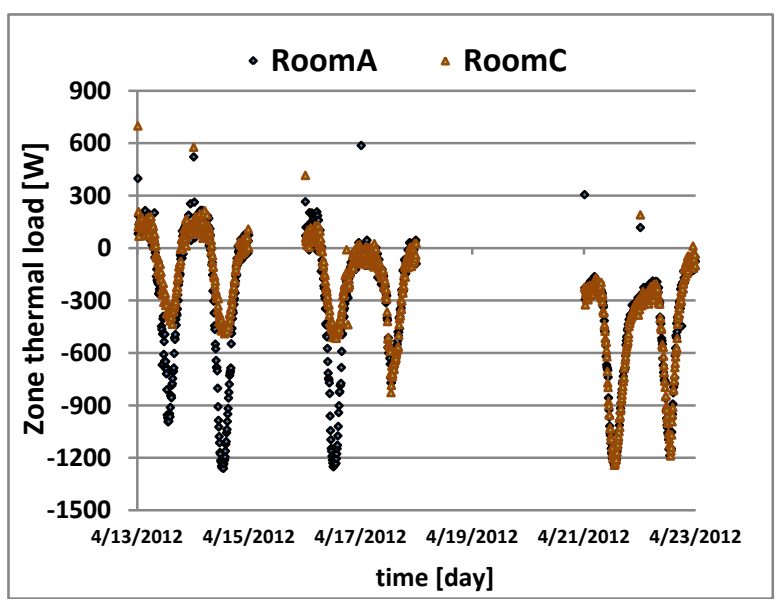

Figure 16 Comparisons between heating and cooling loads derived from measurements obtained in RoomA (static blind) and RoomC (controlled blind)

\section{Conclusions}

The validation results show that the room model of the Modelica Buildings library generates similar results for low and high mass buildings with and without shade compared to other energy simulation tools listed in ANSI/ASHRAE Standard 140. The application shows how the room model of the Modelica Buildings library can be used as part of a simulationbased controls framework of shading. This demonstrates that the room model of the Modelica Buildings library can be used not only for whole building simulations, but also as part of a framework for simulation-based controls operations.

\section{Acknowledgments}

This work was supported by the Assistant Secretary for Energy Efficiency and Renewable Energy, Building Technologies Program of the U.S. Department of Energy under Contract No. DEAC02-05CH11231 and by the California Energy Commission, Public Interest Energy Research Program, Buildings End Use Energy Efficiency Pro- gram, award number 500-10-052. We would like to thank Andrew McNeil for his support in developing and integrating scripts for radiance calculations. We would like to thank Eleanor Lee for allowing us access to the Advanced Windows Test Facility.

\section{References}

[1] M. Wetter, W. Zuo and T. S. Nouidui, "Recent developments of the Modelica buildings library for building energy and control systems," in Proceedings of the 8th International Modelica Conference. Dresden, Germany, March 2011, 2011.

[2] M. Wetter, W. Zuo and T. S. Nouidui, "Modeling of Heat Transfer in Rooms in the Modelica "Buildings" Library," in Proceedings of Building Simulation 2011, Sydney, 2011.

[3] T. S. Nouidui, M. Wetter and W. Zuo, "Validation of the window model of the Modelica Buildings library," in Proceedings of SimBuild2012, Madison, 2012.

[4] ANSI/ASHRAE, Standard Method of Test for the Evaluation of Building Energy Analysis Computer Programs (ANSI/ASHRAE Standard 140-2007), Atlanta: American Society of Heating, Refrigerating and Air-Conditioning Engineers, 2007.

[5] M. Wetter, "Co-simulation of building energy and control systems with the Building Controls Virtual Test Bed," Journal of Building Performance Simulation, vol. 3, no. 4, 2011.

[6] C. Brooks, E. A. Lee, X. Liu, S. Neuendorffer, Y. Zhao and E. A. L. X. L. Haiyang Zhengher, "Ptolemy II - Heterogeneous Concurrent Modeling and Design in Java," Berkeley, 2007.

[7] T. S. Nouidui, M. Wetter, Z. L. Li, X. Pang, P. Bhattacharya and P. Haves, "BACnet and Analog/Digital Interfaces of the Building Controls Virtual Test Bed," in Proceedings of the 12th IBPSA Conference, p. 294--301. Sydney, Australia, November 2011, 2011.

[8] PYTHON. [Online]. Available: http://www.python.org/.

[9] PERL. [Online]. Available: http://www.perl.org/.

[10] RADIANCE. [Online]. Available: http://radsite.lbl.gov/radiance/index.html.

[11] Dymola. [Online]. Available: http://www.3ds.com. 